\title{
aniki
}

Revista Portuguesa da Imagem em Movimento

Portuguese Journal of the Moving Image

\section{Figuras de la otredad en el cine contemporáneo}

\section{Lucas Martinelli}

Universidad de Buenos Aires y Universidad de Tres de Febrero lucasmartinelli.cine@gmail.com

http://orcid.org/oooo-0003-0933-9580

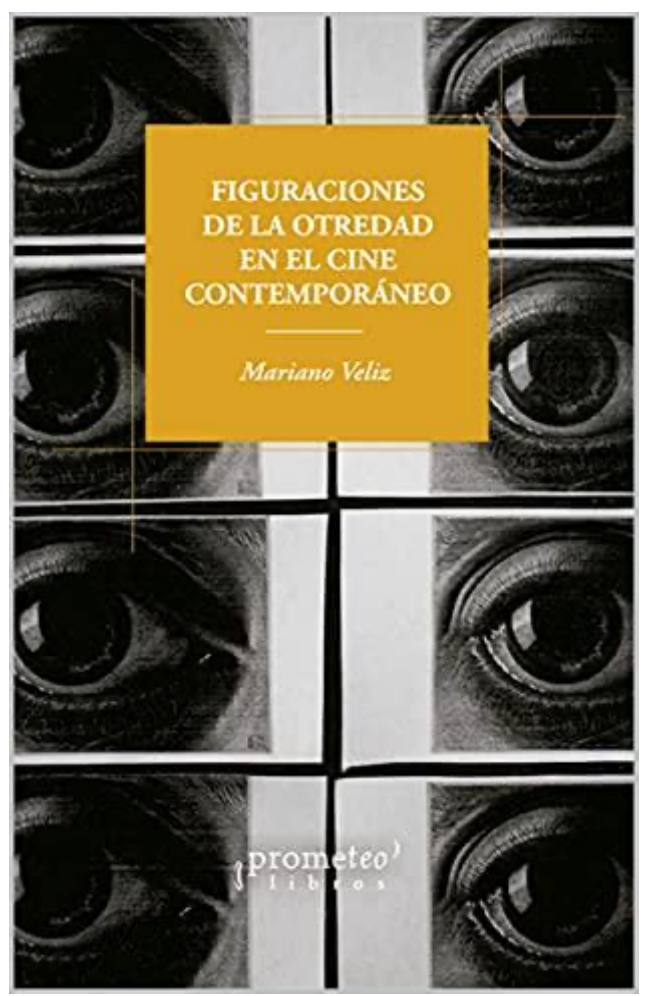

Veliz, Mariano (2021). Figuras de la otredad en el cine contemporáneo. Buenos Aires: Prometeo. 230 P. ISBN 978-987-574-977-9.

Este libro presenta un compendio sobre la estética del gótico desde una trama vinculada con una reflexión profunda sobre la figuración de la otredad en el cine contemporáneo. Entre ambos aspectos, la escritura atraviesa distintas genealogías literarias, conceptualizaciones teóricas y atiende a un corpus de películas para desplegar las incidencias de esos 
trazos en diversos imaginarios simbólicos y semióticos. A partir de una sesuda argumentación filosófica y una corriente analítica precisa, ajustada y metódica, el libro articula una apertura a ocho películas realizadas en las últimas décadas que elaboran posiciones novedosas en torno al gótico y la alteridad.

Dos modalidades de articulación entre la teoría y la crítica aparecen en este trabajo. La primera tiene que ver con las indagaciones teóricas que deslizan posibilidades de pensar más allá de los objetos analizados. Los abordajes que se realizan hacia los filmes dan lugar a un modo de unión que comprende la posibilidad de ver más allá de los mismos, con vectores de análisis centrífugos que hacen del aparato teórico una paleta de filtros por los que tamizar diversos objetos culturales. Por otro lado, el incisivo sustento con el que se reflexiona sobre estos filmes y sus alusiones permite volver a verlos con otros ojos y disfrutar de los hilos conductores de sus potencias creativas. El análisis de las películas resulta un apasionante ejercicio para la mirada y la escucha, una destreza sobre los modos de penetrar y fundirse con esos espacios y temporalidades. El lector podrá corroborar muchas de estas trabajosas e iluminadas reflexiones en cualquier otro filme que construya su mundo en torno a estas sensibilidades fantásticas, horrorosas, siniestras o espectrales que den lugar a una elaboración y anclaje entre lo mismo y lo otro, el uno y su doble.

El selecto corpus fílmico está compuesto por una serie de figuras que organizan las películas en pares. Con raíces en la literatura gótica y los imaginarios de la modernidad, las figuras tratadas son los vampiros, los fantasmas, los autómatas y los dobles, aunque no se limiten a estos seres, sino a las modalidades de otredad que pueden significar. Alimentada por la filosofía y la teoría interesada en la alteridad, la argumentación crítica se constituye en torno a conceptualizaciones sobre la liminalidad, el intersticio, la temporalidad, la espacialidad, la clase, el género sexual, entre otras. Estos aspectos desatan la imaginación y precisan los modos en los que el poder organiza hegemonías visuales, auditivas y culturales. Exploran y revisan el territorio de la otredad, dan lugar a respuestas inteligentes y arman preguntas germinales.

Los rasgos, tópicos y figuras del cruce entre el cine gótico contemporáneo y los modos de inferirse cierta aparición de la otredad se organizan en este libro con un trazo que no piensa lo cronológico de manera lineal, sino que muestra los vínculos como parte de una 
totalidad expansiva, que prolifera en el armado de alteridades y posibilidades de captación de lo divergente.

El vampiro es la primera figura de otredad del libro. Formalizados en el siglo XVII, los rasgos que condensan al vampirismo de algún modo se opondrían al apogeo de la ilustración con la fuerza arcaica propia de la región de los montes Cárpatos. Algo del límite entre Oriente y el Imperio turco otomano se afirma allí, con una indistinción entre los bordes de la vida y la muerte que opera en el seno de la espacialidad de la capilla, el sepulcro y la guarida para amenazar las certezas de la modernidad. Dracula: Pages from a virgin's diary (2002), de Guy Maddin, elaborado sobre un ballet de 1998 a su vez basado en la novela de Bram Stoker, recupera los procedimientos propios del lenguaje de los orígenes del cine. En este caso, la figura del monstruo (sobre la que ha trabajado Michel Foucault, como marco de anormalidad que no atiende las distinciones estancas entre especies, reinos y géneros) permite poner en crisis ciertas nociones que definen culturalmente lo humano desde un lugar intersticial que desafía la naturaleza y tensiona la representación -en este caso de la orientalidad. Criatura de la noche ${ }^{1}$ (Let the Right One In, 2008), de Tomas Alfredson, también elabora la cuestión del vampirismo pero desde un suburbio en las afueras de Estocolmo. La periferia desoladora se distancia del típico paisaje londinense donde se suele narrar al vampiro y el personaje que lo encarna elude de manera variable la asunción de categorías fijas de identidad. Entre lo humano y lo animal, Eli - la niña/niño de este filme - pone en crisis los binarismos, vuelve excéntrica la potencia monstruosa desde un entre-medio que pone en escena estrategias de resistencia organizadas contra las lógicas de los procesos de inclusión y exclusión. Combate contra el orden normalizador de las clasificaciones y arma un cuerpo de la revuelta que se conforma como espacio de saber.

El fantasma es la segunda figura de otredad. Lo que vienen a manifestar las historias de fantasmas es un conflicto entre temporalidades. Las cuestiones que se desprenden están ligadas a pasados no resueltos, legados que justifican retornos, necesidad de cobros, venganzas, justicias o deudas pendientes. Estas narrativas problematizan relaciones revisor). 
entre la mirada y el saber. Los otros (The Others, 2001), de Alejandro Amenábar, yuxtapone rasgos del melodrama familiar, el terror y el thriller como retorno violento de un pasado que busca alguna forma de reparación. En una arquitectura que simboliza el combate entre los vivos y los espectros por la posesión de la propiedad, se enredan las disyunciones temporales entre la ubicación de la historia, los entramados ligados a la clase social y el lugar de la madre o institutriz que ha sido recurrente en este tipo de ficciones. La leyenda del jinete sin cabeza (Sleepy Hollow, 1999), de Tim Burton, activa con su iconografía elementos del modo fantástico y el cine de terror. Desde la caracterización de los personajes, la configuración de los espacios, el estilo fotográfico, hasta la construcción de escenas criminales. Dos espectros que aparecen allí vienen a repudiar la irreversibilidad de la muerte, a hacer que el tiempo vuelva a su cauce y transformar los tiempos por venir.

El autómata es la tercera figura en juego. Si bien los relatos de la creación de la vida que se hace humana existen a lo largo de la historia, la invención del homúnculo (ese ser creado fuera de un útero humano) fue por excelencia un sueño medieval amasado por los alquimistas. Una mitología que dio lugar a diferentes obras maestras que van de Fausto a Frankenstein, la creación de la vida a partir de la materia orgánica, ha tenido diversas interpretaciones. El joven manos de tijera ${ }^{2}$ (Edward Scissorhands, 1990), de Tim Burton, activa diversos dilemas topográficos cuyos esquemas componen una ubicuidad para una demarcación de la otredad. El contraste entre la mansión (donde habitan el monstruo y su científico) y el vecindario se produce de diferentes maneras, pero particularmente por un modo de filmar: si el suburbio se filma por travellings laterales, la mansión gótica de montaña se filma con la emoción propia del movimiento vertical. The Piano Tuner of Earthquakes (2005), de Stephen y Timothy Quay, en contraposición, construye un espacio equívoco, complejo e indeterminado. La isla en la que se desarrolla la historia es un espacio de reclusión y producción que puede interpretarse como un territorio de disputa donde la equiparación de los humanos y los autómatas se hibrida con lo mecánico para impugnar la maquinaria del poder.

${ }^{2}$ Eduardo Manostijeras, en otros países de lengua española (nota del revisor).

aniki Recensões| Reviews 
El doble es la última figura en el orden que se presentan en el libro. La imagen reflejada y el sujeto frente a ella han permitido diversas indagaciones sobre la sombra y la imagen especular. El doble como mito narcisista ha tomado diversas formas. El secreto de Mary Reilly (Mary Reilly, 1996), de Stephen Frears, retoma la novela del Dr. Jekyll and Mr. Hyde para dislocar la posición desde la que se construye el relato. El punto de vista está dado desde el lugar de la criada. Allí, la operación de la mirada, la indagación, el conocimiento y la acción que realiza la protagonista transgrede la perspectiva tradicional con la propuesta de una encarnación que hace suya la problemática identitaria ligada a la clase y el género sexual. Institute Benjamenta (1995), de Stephen y Tomothy Quay, viene a proponer, contra la normalización del poder disciplinario, la posibilidad de quebrar la arquitectura de la vigilancia, la mirada panóptica y las estructuras duales.

El territorio poroso de la otredad encuentra en este libro un recorrido por los diferentes paisajes que presenta el cine gótico contemporáneo. La perspectiva dentro de las ficciones puede percibirse desde la figura del "excéntrico" que en términos relacionales viene a proponer la relatividad del centro que construye la normalidad. Algunos de los personajes excéntricos llevan el foco narrativo y otros son seguidos de cerca por un personaje que los percibe con curiosidad, los descubre de una manera desinteresada. Estas figuraciones directas de la alteridad atisban rasgos de comprensión de la otredad (y claro, de su vínculo con la mismidad) desde una óptica de la resistencia contra la hegemonía del poder, son visiones y escuchas que rasgan la fantasía del uno y, a la vez, de los dualismos. 